\title{
The Comparison of Elite Wrestlers' State of Anxiety Before-after Weighing
}

\author{
Veysel Küçük ${ }^{1}$, Ünsal Tazegül ${ }^{2, *}$, Hamdi Sancaklı ${ }^{1}$, Mehmet Haşim Akgül ${ }^{3}$, A. Serdar Yücel ${ }^{4}$ \\ ${ }^{1}$ Marmara University, School of Physical Education and Sports, İstanbul, Turkey \\ ${ }^{2}$ GaziUniversity, School of Physical Education and Sports, Ankara, Turkey \\ ${ }^{3}$ Mehmet Akif Ersoy, University, School of Physical Educationand Sports, Burdur, Turkey \\ ${ }^{4}$ Frrat University, Faculty of Sports Sciences, Elazig, Turkey \\ *Corresponding author: unsaltazegul@hotmail.com
}

Received April 09, 2015; Revised April 22, 2015; Accepted May 08, 2015

\begin{abstract}
Anxiety is one the significant factor which affects performance of athletes in a negative way. The purpose of this research is to compare elite wrestlers' state of anxiety before-after weighing. A state of anxiety inventory developed by Spielberg and adapted to Turkishby Ömer and Le Compte has been used in order to detect wrestlers' state of anxiety before-after weighing. SSPS 20 package software has been used while analyzing the data on this research. After it has been stated that datum has both an homogenous and normal distribution; it has been decided that parametric test method should be used in statistic analysis. In statistic analysis, diagnostic statistic and co-sample $t$ test has been implemented. On the consequence of these analyses, the wrestlers' state of anxiety before weighing has been higher than the state of anxiety that wrestlers have after weighing.
\end{abstract}

Keywords: state of anxiety, wrestlers, weighing

Cite This Article: Veysel Küçük, Ünsal Tazegül, Hamdi Sancakll, Mehmet Haşim Akgül, and A. Serdar Yücel, "The Comparison of Elite Wrestlers' State of Anxiety Before-after Weighing." American Journal of Sports Science and Medicine vol. 3, no. 2 (2015): 35-38. doi: 10.12691/ajssm-3-2-2.

\section{Introduction}

Anxiety, in terms of dictionary meaning, is a negative feeling that it is felt while facing with either a dangerous or unexpected condition $[1,2,3]$.

The state of anxiety is subjective fear that an individual feels it due to a stressful situation [4].

Stress and anxiety can affect ability of making right decisions negatively in athletes' attitude. An athlete, who is under anxiety and stress, is unable to make right decisions and to perform his/her ability however S/he desires. Athletes, who are under extreme pressure, might have inappropriate behaviors. Not only stress makes athletes forget the actions which is well known and performed by athletes many times in trainings but also it causes athletes to perform negative actions while raising a chaos in athletes' feelings [5].

Today, it has been mentioned that there are many factors affecting athletes' sportive efficiency level. While some parts of these factors are evaluated under the name of environmental factors; some other parts of these factors are evaluated as internal factors. Athletes' psychological preparations are significant factors to be successful in performing sports. Athletes' psychological conditions and their performances are in a close relation with their level of anxiety [6,7].

As long as the researches which show relation between athletes' psychological state and their performance progress; sportive actions has gained a different dimension and it has been detected that mental activitiessuch as intelligence, attention, memory, self control, judgment, comparison, analyzing, anxiety are included in all these sportive activities [8].

It has been adopted that Anxiety affects performance in the researches which are carried out in the field of sport psychology. It should be taken care of that anxiety will not affect performance in a negative way and there should be techniques in order to cope with these situations [9].

Presence of external reinforcement and punishments, uncertainty of conclusion, dominance of opponent, scores athletes have in latest competitions, at what degree of importance of these scores have according to athletes, how athletes comprehend their physical, technique, tactic physiological capabilities as compared to their opponents' capabilities, stress and anxiety are definitive in all competitive environment and especially researches which are carried out in high level sports [10].

Every competition has a great deal of significance for athletes in terms of social and economical factors. In accomplishing success, the ability of coping with anxiety an extremely important criterion no matter how perfect an athlete is in terms of physical features and no matter how perfect training duration is. Psychological preparation should be different in accordance with fundamentals of different sports. Team sports have different dynamics compared to individual sports. It has been thought that individual athletes have more intense anxiety level than team sport athletes [11,12]. 
Scientists have developed new training systems in order to increase athletes' performances to the top level. Researches carried out by scientists shows that not only physical trainings is not merely significant to increase athletes performances but also psychological factors have a significant place in athletes progress $[13,14]$.

The world's most successful athletes believe that the hardest athlete to dominate is athletes themselves. If an athlete learns to dominate his/her previous success; s/he learns easily how to dominate other athletes. For this reason, athletes should know what retains him/her from his/her goals [15].

The purpose of this research is to compare elite wrestlers' state of anxiety before-after weighing.

\section{Material and Method}

\subsection{Samples}

Samples of this study consist of 40 elite wrestlers who attended Young wrestlers' Turkey Championship in 2012. 95 wrestlers were met and 40 wrestlers out of these were decided to be in this research.

\subsection{The Purpose of Gathering Information of the Research}

A state of anxiety inventory developed by Spielberg (1970) and adapted to Turkishby Ömer and Le Compte (1985) has been used in order to detect wrestlers' state of anxiety before-after weighing. This inventory is a selfevaluation questionnaire that consists of short statements. It has been declared that Alpha reliability is between .83 and .87. Repetition of test reliability is between .71 and .86. Article reliability is between .34 and .72 [16].

\subsection{Analysis of Data}

SPSS 20 package software has been used for the analysis of data. Kolmogorov-Smirnov test has been used in order to have whether data had a normal distribution or not. Therefore, it has been found that data has had a normal distribution. Later on, Anova-Homogenety of variance test has been used in order to evaluate whether data has not had a homogeneous. After that, it has been found that data has had a homogeneous result. After the first examination; parametric test technique has been decided to be used in the statistical analysis of examined data. Diagnostic statistic and co-sample t test has been used.

\section{Results}

In this section, results which have been found at the end of statistical analysis have been given in 2 different charts and graphics.

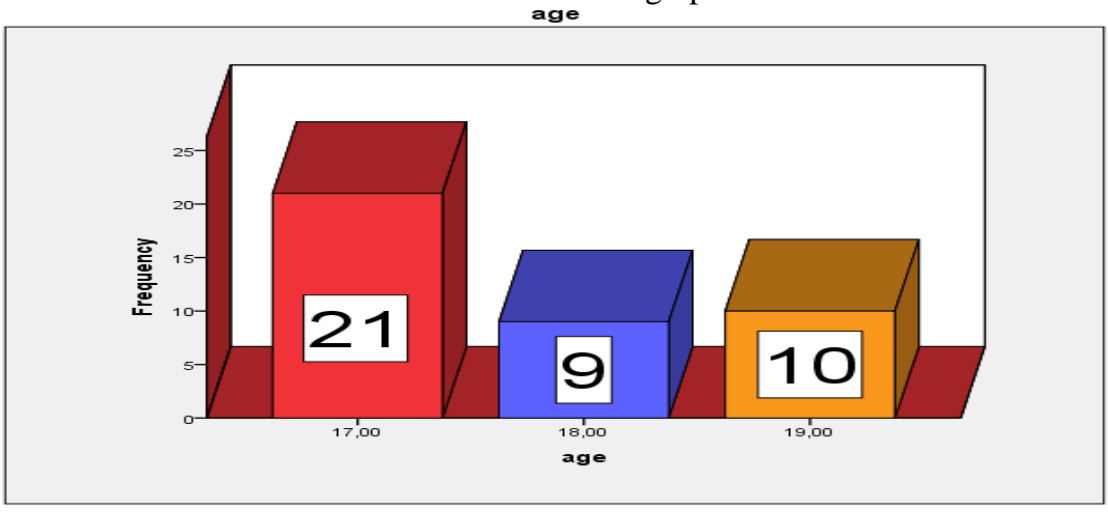

Graphic 1. Distribution of athletes' age who have attended this stud

On this chart, the data and distribution of athletes who have attended in this research have been given above. 21 wrestlers who are 17, 9 wrestlers who are 18, 10 wrestlers who are 19 have attended. 40 wrestlers attend this study in total.

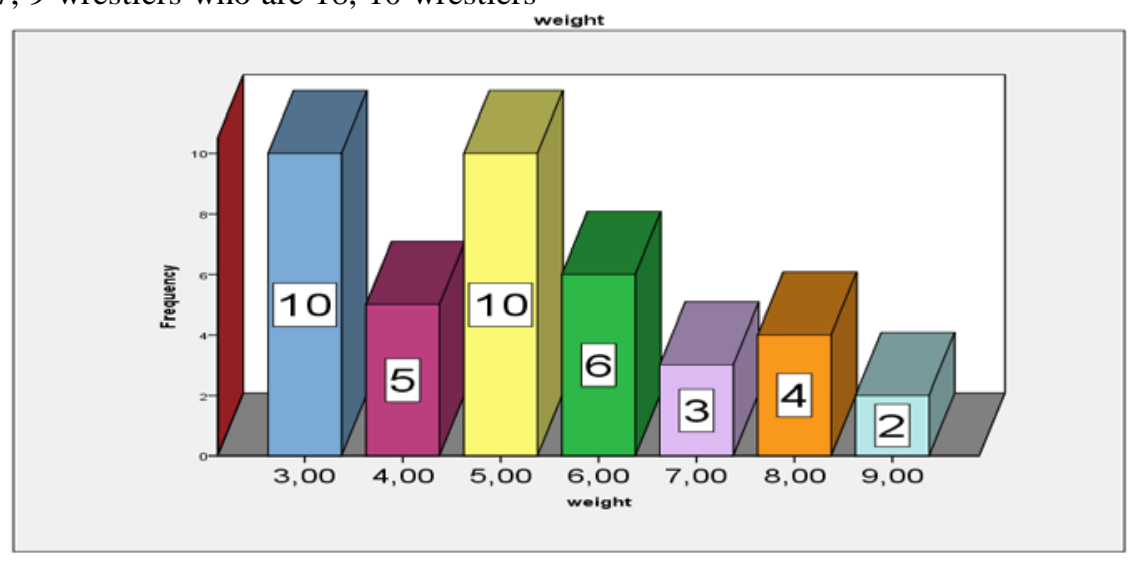

Graphic 2. The frequency distribution that shows wrestlers' pre-match weight loss

Reviewing graphic above, it has been determined that 10 wrestlers have lost 3 kilos, 5 wrestlers have lost 4 kilos, 10 wrestlers have lost 5 kilos, 6 wrestlers have lost 6 kilos,
3 wrestlers have lost 7 kilos, 4 wrestlers have lost 8 kilos, 2 wrestlers have lost 9 kilos. 
Chart 1. The results of diagnostic statistic of state of anxiety

\begin{tabular}{|c|c|c|c|}
\hline & $\mathrm{N}$ & $\overline{\mathrm{X}}$ & \pm \\
\hline Level of anxiety at pre-weighing & 40 & 48,850 & 6,228 \\
\hline Level of anxiety at post-weighing & 40 & 37,400 & 11,160 \\
\hline
\end{tabular}

Reviewing diagnostic statistics which have shown the wrestlers' level of anxiety on chart 1, it has been determined that pre-weighing has been $(=48,850 \pm 6,228)$ and post-weighing has been $(=37,400 \pm 11,160)$.

Chart 2. The Results of co-sample t test

\begin{tabular}{|c|c|c|c|}
\hline Mean & Std. Deviation & $\mathrm{T}$ & $\mathrm{p}$ \\
\hline 11,45000 & 8,42448 & $-8,596$ &, 000 \\
\hline
\end{tabular}

As a consequence of comparison of wrestlers' preweighing and post-weighing state of anxiety points on chart 2, a reasonable difference has been found statistically $(\mathrm{p}<0,05)$.

\section{Discussion}

Reviewing elite athletes' pre-weighing and postweighing state of anxiety scores, it has been understood that measure score which has been carried out 30 minutes before weighing is higher than the score which has been carried out 1 hour after weighing. In addition to the consequence of comparisons of anxiety scores at preweighing and post weighing; a reasonable difference has been found statistically $(\mathrm{p}<0,05)$. After analyzing results, many studies covering wrestlers and other branches have been attained. However, the study which compares level of anxiety at pre-weighing and post-weighing has not been found. Özbay compares national professional wrestlers' state of anxiety at pre-game and post-game. As a result of this comparison, he has determined that there is a reasonable difference statistically. Özbay has determined (2012)that post-game state of anxiety of wrestlers who are over-weight is lower than the ones who have both less over-weigh problems and none over-weigh problems.

Morgan (1970) apply 3 types of IPAT parallel anxiety test to 7 university wrestlers at Missouri university. The first test has been given before the season starts. The second test has been given before the game that is considered as an easy game by the coach. The third test has been given before the game that is considered as a hard game by the coach. Surprisingly, anxiety results that have been identified before games have been lower than the ones that are during pre-season anxiety results. However, there is no difference between easy games and hard games in terms of anxiety results. Afterwards, Morgan and Hammer have applied same IPAT anxiety test to four wrestlers who are from different colleges. Anxiety test have been given orderly at the beginning of the season, during the tournament, after wrestlers prepared (4 hours before the tournament), 1 hour before the first game and 15 minutes after tournament. It has been observed that anxiety has been increased 1 hour ago before the game.It has been noticed that anxiety has been decreased after tournament. It has been identified that anxiety level in real conditions have been lower compared to previous tests at later tournaments [17].

Morgan and Hammer have found that pre-game state of anxiety have been higher than post-game state of anxiety in the research on 29 wrestlers [18].
Screiber (2004)statedthat an increase might be seen on wrestlers' performances by preventing negative influences and state of anxiety [19].

Tazegüland his friends stated in their studies which were carried out in 2015 that wrestlers' anxiety score was lower than boxer, kick boxers were [20].

Çoksevimand his friends observed pre-game, post-game state of anxiety of kick boxers and short-time tempo. They found (2008) found a reasonable difference in statistical analysis [21].

In the meetings when wrestlers have weighed, it has been asked some questions about wrestlers' condition and how wrestlers have felt themselves. As a result of these questions, wrestlers' biggest concern is whether they are on the right weigh that they are expected to or not. Therefore they generally don't eat anything until the weighing time. In addition to meetings having been carried out, wrestlers have experienced some kind of anxiety on their mind that they think their performance level would decrease according to their weight loss. Rather than that wrestlers want to eat something as soon as they finish weighing. Therefore, the biggest reason why wrestlers have high anxiety scores is not being able to reach aimed weigh in accordance with their performance level. According to Martens, the state of anxiety during pre-game might affect both in-game performance and result of the game [22]. Jones and his friends (1993) stated that anxiety has a significant impact on performance [23].

A meeting with Dr Hamdi who was a grek romen national team coach once states his thoughts on his observation below:

Weight loss that is planned both by athlete and by coach, weight loss duration and amount of lost weight might affect the state of anxiety at pre-game. If an athlete decides to lose weight by his own will not obeying what coach says, an increase will be seen in athlete's performance. Also, Wrestlers who lost weight because of coach's will had an unpleasant situation while weighing. They did not even want to be weighed.

It has been believed that power decrease related to weight loss increases the state of anxiety. An athlete who feels powerless might be affected his/her state of anxiety in a sport branch that is based on power and advanced performance such as wrestling. Koral J. and Dosseville F. (2009) have found as a result of their studies that wrestlers who have sudden weight loss have low performance conditions [24]. Roemmich and Sinning (1997) have stated as a result of their studies that wrestlers who have lost weight have low performance conditions [25].

Civan and his friends (2010) compared state of anxiety and continuous anxiety of individual athletes and team athletes at pre-game and post-game. As a result of this comparison, it was found that average state of anxiety scores had different results in different sport types. Average score of state of anxiety had the highest score in individual sports. Team athletes' state of anxiety average score was found that it had a lower score than individual athletes had $(\mathrm{P}<0,05)$. It was found that continuous anxiety at post game between individual athletes and racket based sport had no reasonable relation. However, it was found that team sport athletes' continuous anxiety average score had a higher score than individual athletes and racket based sport athletes had. 
Consequently, it has been found that wrestlers have a high state of anxiety at pre-weighing. Meetings with national team athletes and national team coach result in that one of the significant reason why wrestlers have thoughts on their mind that they will not be able to lose weight they desire along with their performance level.

\section{References}

[1] Güney, S., Terminology dictionary of behavioral sciences and management psychology, Ankara, 1998.

[2] Gürgün O.A., Psychology dictionary İnkilap Book Store, İstanbul 1991.

[3] Hançerlioğlu, O., Mental science dictionary, $2^{\text {nd }}$ press. Remzi Book Store, Istanbul, 1993

[4] Türkçapar Ü (2012). Analysis of wrestlers continuous anxiety levels in terms of different variables, GEFAD / GUJGEF 32 (1): 129-140.

[5] Tazegül Ü.(2012). Comparison of handling styles with stress in individual sport, of Sports and Performance Researches, 3(2), 1322.

[6] Gülșen, D. (2008). Analysis of problem solving ability of players who play at different leagues in terms of their positions, education status and their age, Published Master Degree Thesis, Çukurova University: Adana.

[7] Karabulut A. (2013). Analysis of 13-15 aged football players' state of anxiety in different conditions, Ahi Evran Universty Kırşehir Education faculty Journal, 14,(1), 243-253.

[8] Erbas MK. Relation between state of anxiety andperformance of advanced basketball players, Dumlupınar University, Social Science Institution, Master DegreeThesis, Kütahya, 2005.

[9] Koy F, (1999). Comparison of state of anxiety of optimum level with perform ancen basketball players, Hacettepe Journal of SportScience, (10), 1, 30-40

[10] Gümüş M. analysis of the state of anxietys cores of professional football clubs, Sakarya University, Social Science Institution, Master Degree Thesis, Sakarya, 2002.

[11] Civan, A.,Arı,R., Görücü, A., Özdemir, M. comparison of team athletes' and individual athletes state of anxiety and continuous anxiety at pre-game and post-game, International Journal of Human Science, 2010,193-206.
[12] Konter, E., theory of psychological preparation in sport. Bağırgan Publishing Center, Ankara, 1998.

[13] Tazegül Ü. (2012). Comparison of the style of coping with stress of athletes in the individuals ports branches in sociodemographicrespectbranchesinsociodemographicrespeIntern ationalJournalof Sport Studies. Vol., 2 (2), 89-94.

[14] Tazegül Ü. (2013). The Determination of the Relationship Between Motivational Trends and the Style of Coping with Stress, World Applied Sciences Journal21 (1): 08-14.

[15] Biçer T. Top Performance, Beyaz Publications, Istanbul, 1998.

[16] Öner, N., Le Compte, A. 81998). Discontionary and contionary anxiety inventory book ( $2^{\text {nd }}$ Pres) Boğaziçi University Publishing center, İstanbul.

[17] Özbay, S. (2012). Comparison of adult national wrestlers' state of anxiety at pre-game and post-game, Karamanoğlu Mehmetbey University Social Science Institution, Physical education department Master Degree Thesis

[18] Artok F.(1994). The effect of state of anxiety on interuniversity basketball tournament players at pre-game .Master degree thesis, Adana.

[19] Screiber, D.S. (2004). To get rid of stress, anxiety and depression, İstanbul: Elipsis Publishing, 2004.

[20] Tazegül, Ü,. Küçük, V., Tuna, G., Akgül, M.H. (2015).Comparison of Continuous Anxiety Level of Some Individual Fight Athletes, American Journal of Applied Psychology, 3(2), 22-26.

[21] Çoksevim B., Sarıtaş N., Kaya M., Pepe O. (2008) state of anxiety and continuous anxiety of kick-box athletes at pre-game and postgame, short terms inventory results, Turkey Kick Box Federation Sport Science Journal (1),:1, 23-27.

[22] Martens, R., Burton, D., Vealey, R., Bump, L., and Smith, D. (1990). Development and validation of the Competitive State Anxiety Inventory-2 (CSAI-2. Competitive anxiety in sport IL: Human Kinetics. 1990, 117-213.

[23] Jones, G., Swain, A., and Hardy, L.. (1993). Intensity and direction dimensions of competitive state anxiety and relationships with performance. Journal of Sports Sicences, 1993, (11), 6, 525532.

[24] Koral J.,Dosseville F. (2009) Combination Of Gradual And Rapid Weight Loss: Effects On Physical Performance And Psychological State Of Elite Judo Athletes, Journal of Sport Science, January 15th, 27(2): 115-120.

[25] Roemmich J. N., Sinning W. E. (1997) Weight Loss AndWrestling Training: Effects On Growth-Related Hormones. JAppl Physiol, June 1, 82 (6): 1760-1764. 